\author{
Katia Sampieri · Theodora Hadjistilianou \\ Francesca Mari · Caterina Speciale \\ Maria Antonietta Mencarelli · Francesco Cetta \\ Siranoush Manoukian · Bernard Peissel \\ Daniela Giachino - Barbara Pasini - Antonio Acquaviva \\ Aldo Caporossi · Renato Frezzotti · Alessandra Renieri \\ Mirella Bruttini
}

\title{
Mutational screening of the $R B 1$ gene in Italian patients with retinoblastoma reveals 11 novel mutations
}

Received: 7 September 2005/ Accepted: 6 November 2005 / Published online: 4 February 2006

(C) The Japan Society of Human Genetics and Springer-Verlag 2006

\begin{abstract}
Retinoblastoma (RB, OMIM\#180200) is the most common intraocular tumour in infancy and early childhood. Constituent mutations in the $R B 1$ gene predispose individuals to RB development. We performed a mutational screening of the $R B I$ gene in Italian patients affected by RB referred to the Medical Genetics of the University of Siena. In 35 unrelated patients, we iden-
\end{abstract}

K. Sampieri $\cdot$ F. Mari $\cdot$ C. Speciale $\cdot$ M.A. Mencarelli

A. Renieri · M. Bruttini $(\square)$

Medical Genetics, Molecular Biology Department,

University of Siena, Policlinico Le Scotte,

viale Bracci 2, 53100 Siena, Italy

E-mail: bruttinim@unisi.it

Tel: + 39-0577-233259

Fax: + 39-0577-233325

T. Hadjistilianou · A. Caporossi

Ophtalmological Science and Neuroscience,

Siena General Hospital, Siena, Italy

F. Cetta

Surgery Department, University of Siena,

Siena, Italy

S. Manoukian · B. Peissel

Medical Genetics, Experimental Oncology,

Instituto Nazionale Tumori, Milan, Italy

D. Giachino

Medical Genetics SSD, ASO San Luigi Orbassano,

Turin, Italy

B. Pasini

Genetics, Biology and Biochemistry Department,

University of Torino, Turin, Italy

A. Acquaviva

Pediatrics Department, University of Siena,

Siena, Italy

R. Frezzotti

University of Siena, Siena, Italy tified germline $R B 1$ mutations in 6 out of 9 familial cases $(66 \%)$ and in 7 out of 26 with no family history of RB $(27 \%)$. Using the single-strand conformational polymorphism (SSCP) technique, 11 novel mutations were detected, including 3 nonsense, 5 frameshift and 4 splicesite mutations. Only two of these mutations (1 splice site and 1 missense) were previously reported. The mutation spectrum reflects the published literature, encompassing predominately nonsense or frameshift and splicing mutations. $R B 1$ germline mutation was detected in $37 \%$ of our cases. Gross rearrangements outside the investigated region, altered DNA methylation, or mutations in non-coding regions, may be the cause of disease in the remainder of the patients. Some cases, e.g. a case of incomplete penetrance, or variable expressivity ranging from retinoma to multiple tumours, are discussed in detail. In addition, a case of pre-conception genetic counselling resolved by rescue of banked cordonal blood of the affected deceased child is described.

Keywords $R B 1$ gene $\cdot$ Italian population · Retinoblastoma $\cdot$ Mutation screening

\section{Introduction}

Retinoblastoma (RB; OMIM \#180200) is a childhood malignant eye tumour originating from progenitors of retinal sensory cells, with an incidence of 1 case in every 15,000-28,000 live births (Gallie et al. 1999). Inactivation of both alleles of the $R B 1$ gene (GenBank accession no. L11910), within chromosome band $13 \mathrm{q} 14.2$, is the cause of tumour development. Approximately $40 \%$ of RB cases are hereditary, with bilateral and/or multifocal tumours, while the other $60 \%$ are sporadic cases presenting with unilateral disease (Vogel 1979). 
In most sporadic RB cases, two mutational events have occurred in somatic cells, neither of which is present in DNA from constitutional cells (Schimizu et al. 1994; Lohmann et al. 1997; Klutz et al. 1999). However, nearly $15 \%$ of unilaterally affected patients have a germline RB1 mutation, representing a $45 \%$ risk for their offspring (Alonso et al. 2001). In the familial and bilateral form of RB, the first mutational event is a germline mutation, either transmitted from an affected parent as an autosomal dominant trait with high penetrance $(90 \%)$, or acquired during gametogenesis or gestation (Knudson 1971; Comings 1973). The inactivation of the second $R B 1$ allele is somatic and results in multiple, and often bilateral, tumours.

The presence of $R B I$ germline mutations also confers an increased risk of developing second primary tumours, with a cumulative incidence of $22 \%$ by the age of 25 years (Moll et al. 2001). In fact, loss of function of the $R B I$ gene is associated not only with $\mathrm{RB}$ but also with a variety of other tumours, such as osteosarcoma, small cell lung carcinoma, bladder tumour, and breast carcinoma (Wadayama et al. 1994; Lee et al. 1988; Hansen et al. 1985).

The identification of a broad spectrum of nearly 500 distinct somatic or germline mutations resulting in $R B 1$ gene inactivation in $\mathrm{RB}$, is the basic information required to develop rapid procedures for mutational analysis as well as to understand the molecular mechanisms underlying different degrees of penetrance or expressivity of the disease (Lohmann 1999; Alonso et al. 2001; Richter et al. 2003; Tsai et al. 2004; Houdayer et al. 2004; Harbour 2001). Here, we report our experiences of genetic counselling and molecular diagnosis at our centre during the last 5 years in a cohort of 35 patients.

\section{Materials and methods}

\section{Patients}

This study includes 35 unrelated cases of RB with different clinical presentations: 7 familial bilateral, 2 familial unilateral, 13 sporadic bilateral and 13 sporadic unilateral cases. Blood samples were obtained from patients and available parents after informed consent. DNA was extracted from peripheral blood using a QIAamp DNA Blood Kit (Qiagen, Hilden, Germany) or by the phenol/chloroform method (Sambrook et al. 1989).

\section{Molecular analysis}

Genomic DNA was amplified by polymerase chain reaction (PCR). Primers and PCR conditions used for single exons and promoter analysis were as described previously (Hogg et al. 1992; Scheffer et al. 2000; Houdayer et al. 2004).
Single-strand conformational polymorphism (SSCP) was performed on a Genephor apparatus (Pharmacia Amersham, Little Braunschweig, Germany) using a GeneGel Excel 12.5/24 Kit (Pharmacia Amersham). PCR products were mixed with an equal volume of formamide, denatured by heating at $95^{\circ} \mathrm{C}$ for $5 \mathrm{~min}$ followed by immediate chilling on ice. Fragments showing altered mobility relative to controls were directly sequenced. Amplicons were purified and sequenced in both directions using the BigDye Terminator Cycle Sequencing V1.1 Ready Reaction Kit (Applied Biosystems, Foster City, CA) with incorporation of PCR oligonucleotides as extension primers and following electrophoresis in an ABIPrism 310 Genetic Analyzer. The analysis was performed using the Collection and Sequence Analysis software package (Applied Biosystems). The results were compared with the reference RB1 genomic sequence (GenBank accession no. L11910.1). The putative consequences of the DNA variations were deduced from $R B 1$ cDNA (NCBI accession NM_000321.1) and protein (NCBI accession NP_000312) sequences.

Negative cases were analysed by real-time quantitative PCR. The TaqMan probe and primers were designed using Primers Express software (Applied Biosystems). The $R B 1$ probe is complementary to a segment located in exon 17. $R B 1$ exon 17 forward primer: $5^{\prime}$-AACACATT TGTCTTTCCCATGGATTCT-3'; $R B 1$ exon 17 reverse primer: 5'-GCCTTCTGCTTTGATAAAACTTTCGA3'; $R B 1$ exon 17 TaqMan probe: 5'-AATGTGCTTAAT TTAAAAGCC- $3^{\prime}$. The $R B 1$ probe contained a fluorophore $5^{\prime}$ FAM as a reporter. The size of the amplicon was 91 bp. An RNAaseP kit was used as an internal reference (Applied Biosystems). In order to validate the presence of the identified deletion, a microsatellite analysis was performed using two intragenic polymorphic markers located in intron 2 (Rbi2/ D13S153), and in intron 20 [RBi20/CTTT(T) repeat] of the $R B 1$ gene, respectively (Alonso et al. 2001). The aplotype of each tested sample was assessed by gel electrophoresis.

\section{Results}

During the last 5 years, 35 Italian RB patients have been referred to our centre for genetic counselling and molecular diagnosis. Concerning inheritance, 9 were familial cases, ( 2 unilateral and 7 bilateral), and 26 were sporadic cases, (13 unilateral and 13 bilateral). The whole coding region (27 exons) and nearby intronic regions were screened by PCR-mediated SSCP analysis followed by direct DNA sequencing. In 12 cases, a causative point mutation was identified. The negative cases were then analysed by the recently developed realtime quantitative PCR method and one deletion was identified. This deletion was confirmed by microsatellite analysis (Rbi2 and RBi20 markers). In total, we identified a causative $R B 1$ mutation in 13 out of 35 patients (mutation rate of $37.1 \%$ ). In particular, 7 patients have 
Table 1 Identified mutations. Nucleotide numbering for genomic DNA and cDNA are according to GenBank accession numbers L11910.1 and NM_000321.1, respectively. Amino acid numbering refers to the reference sequence for pRB protein, NP_000312. $S$ Sporadic, $F$ familiā, $U$ unilateral, $B$ bilateral, $m f$ multifocal, $u f$ unifocal

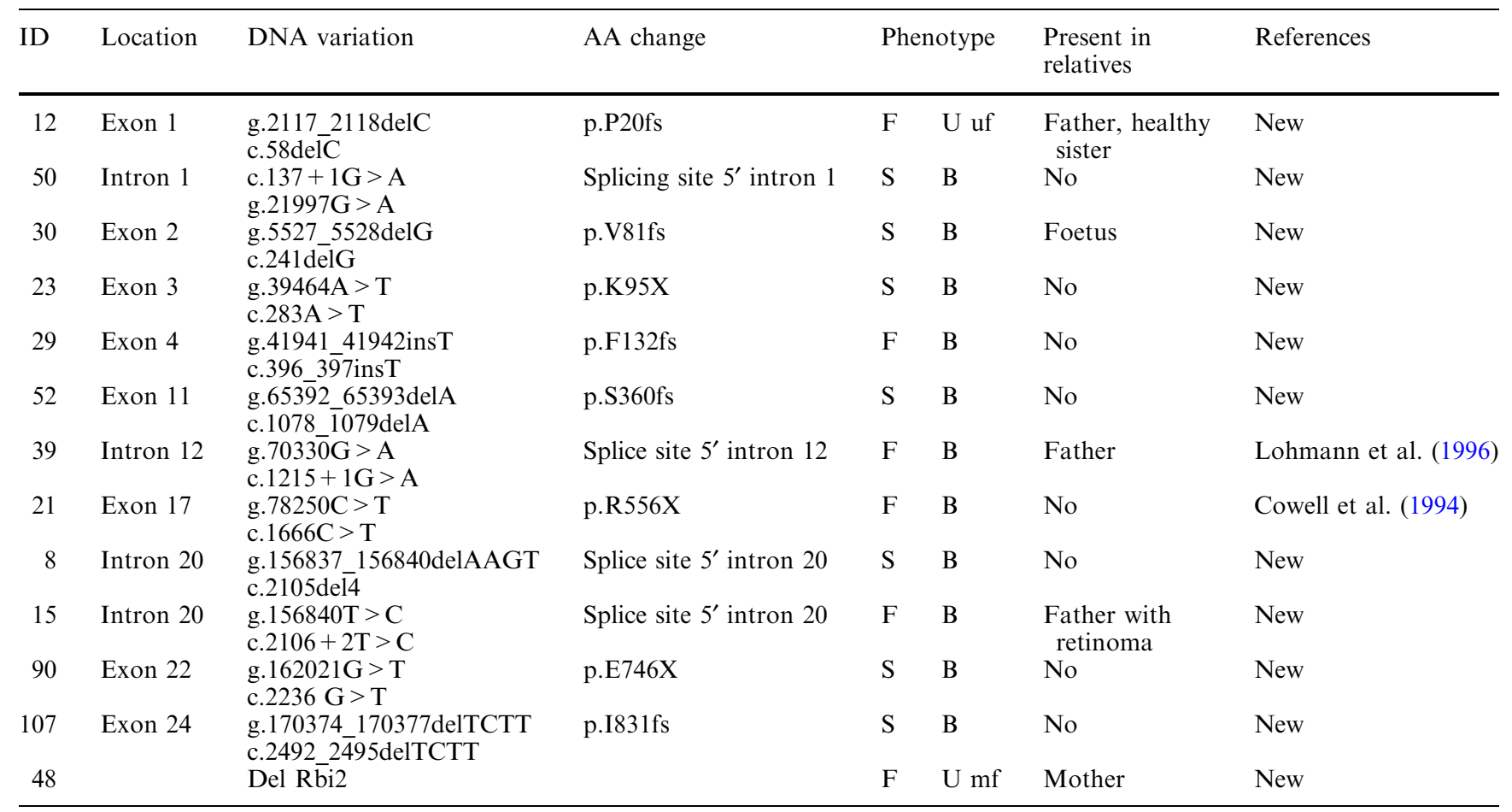

bilateral sporadic RB, and 6 patients had familial RB, 2 unilateral and 4 bilateral. These results are summarised in Table 1.

Eleven were novel mutations. Only two mutations were previously reported: one is a $\mathrm{G}$ to A substitution at the first intronic base of the exon 12 donor splice site (g.70330G > A) and the other is a nonsense mutation in exon 17 due to a single $\mathrm{C}$ to $\mathrm{T}$ substitution (g.78250C > T) (Lohmann et al. 1996; Cowell et al. 1994). Of the 11 novel mutations, 3 were nonsense (p.K95X, p.R556X and p.E746X), 5 were frameshifts, including 4 deletions (g.2117_2118delC, g.5527_5528delG, g.65392_65393delA, g.170374_170377delTCTT) and 1 insertion (g.41941_41942insT), and 4 were splice site mutations. Among splice site changes, three were point mutations (g.21997G > A, g.70330G > A, g.156840T >C) whereas one was a deletion of four bases (g.156837_156840delAAGT) involving the donor splice site of exon 20. Five cases of particular interest are discussed in detail.

\section{A case of non-penetrance}

The female proband was diagnosed with unilateral RB at the age of 14 months during a screening program (Fig. 1a). Her father was enucleated at the age of 15 months for a suspected RB. Mutational analysis of DNA from peripheral blood documented the frameshift mutation c.58delC. The same mutation was also found in her father. Extension of the analysis to other at risk family members revealed the presence of the same point mutation in the healthy older sister, aged 11 ; she therefore represents a case of incomplete penetrance.

A case of retinoma

The male proband underwent right eye enucleation at the age of 4 months (Fig. 1b). After 1 year of chemotherapy for controlateral disease, he underwent enucleation of the left eye. Monolateral retinoma was found in the father after diagnosis in the child. Molecular analysis of the $R B 1$ gene revealed the same splicing mutation in the proband and in his father (c.2106 $+2 \mathrm{~T}>\mathrm{C}$ ). This is a case of variable expression of the disease.

\section{A case of adenocarcinoma of ethmoid sinus}

A left-eye RB was diagnosed early in the proband, who was treated with radiotherapy during the first months of life (Fig. 1c). She underwent right-eye enucleation at the age of 3.5 years followed by radiotherapy and chemotherapy for a controlateral tumour. At the age of 22 years, the patient developed a left ethmoidal adenocarcinoma identified by nasal biopsy. The neoplasia extended to the ethmoid, nasal fossa, left maxillary sinus, medial and inferior orbital paries and rhinopharynx. Mutation analysis of the patient and her relatives 


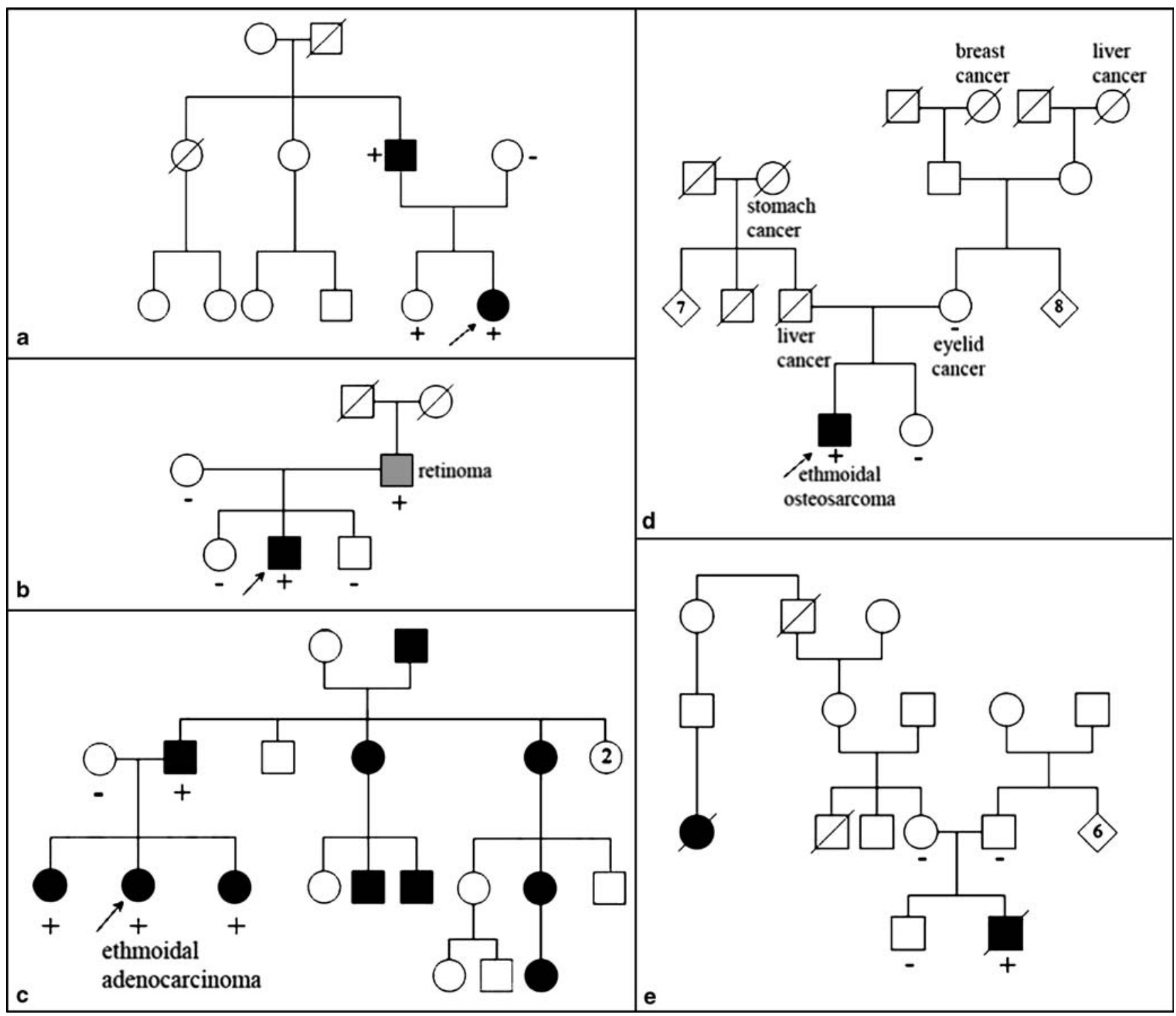

Fig. 1a-e Pedigrees of five families with retinoblastoma (RB). Black symbols Patients with at least RB, grey symbol patient with retinoma, + presence of mutation. a Case of non-penetrance (case 12 in Table 1). b Case of retinoma (case 15 in Table 1). $\mathbf{c}$ Case of coexistence of RB and adenocarcinoma (case 39 in Table 1). d Case of RB associated with osteosarcoma (case 50 in Table 1). e Case of pre-conception genetic counselling (case 107 in Table 1) identified a mutation in the donor site of intron 12 , c. $1215+1 \mathrm{G}>\mathrm{A}$. The same mutation was identified in several other relatives affected by isolated RB.

\section{A case of ethmoidal osteosarcoma}

The proband developed RB at the age of 6 months on the right eye, and a controlateral tumour at the age of 2 years (Fig. 1d). He underwent bilateral eye enucleation followed by radiotherapy only on the right eye. At the age of 24 years the patient showed right ethmoidal osteosarcoma. The patient is alive and healthy at 28 years old. Molecular analysis revealed the point mutation $\quad$ c. $137+1 \mathrm{G}>\mathrm{A} \quad($ or $\operatorname{IVS} 1+1 \mathrm{G}>\mathrm{A})$. The mutation was absent in the mother and in the sister. The mutation is probably "de novo", although the father was not investigated (died at the age of 45 of post-HCV cirrhosis cancer).

\section{A case of pre-conception genetic counselling}

A couple asked for pre-conception genetic counselling as their second-born child died of RB 2 years earlier (Fig. 1e). The couple described that the child presented at 3 years of age, with bilateral and multifocal RB. Despite left enucleation followed by brachytherapy and 


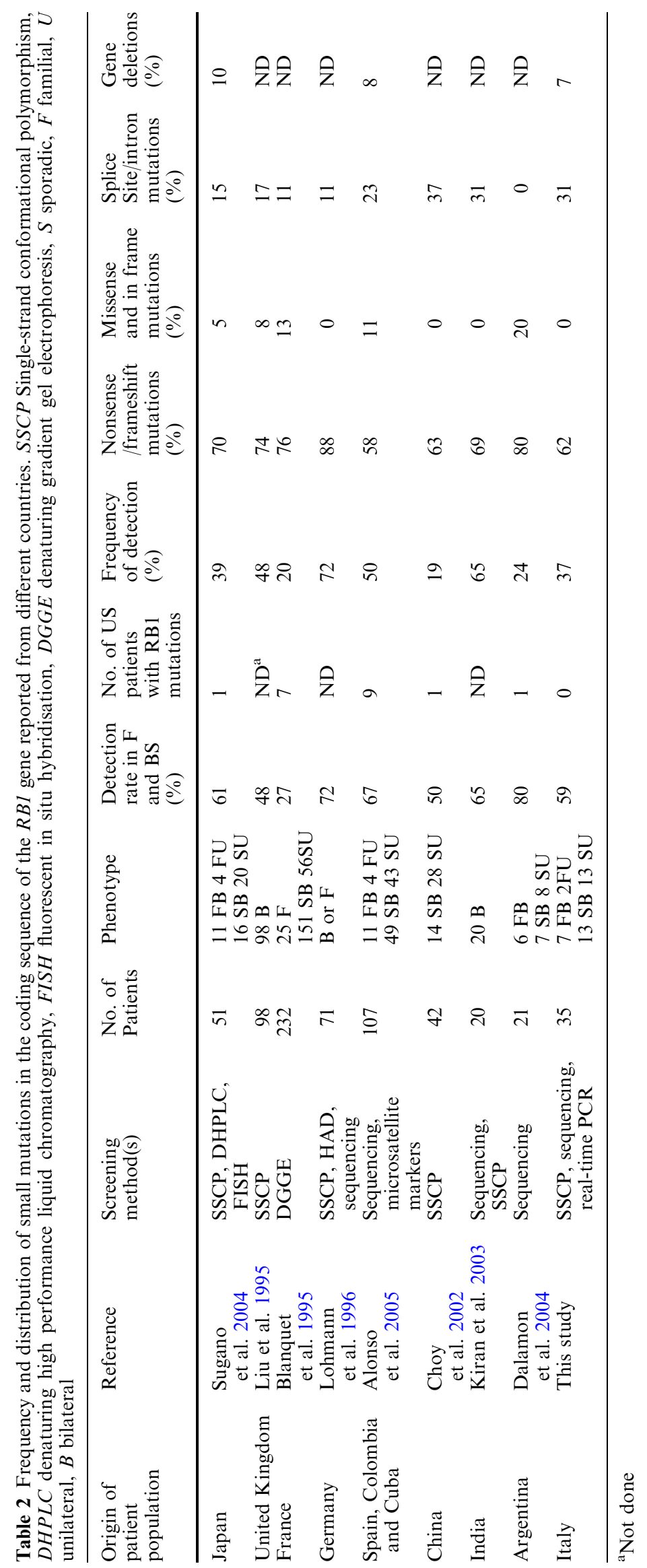


chemotherapy, the child died thereafter with progressive disease. Cordonal blood collected at birth was recovered from a cordonal blood bank. The DNA extracted revealed the presence of a frameshift mutation, c.2492_2495delTCTT. The compatibility both of maternity and paternity in respect to the recovered DNA was confirmed by the analysis of 12 polymorphic loci. The mutation was not present in either parent although unilateral RB was reported in a far relative of the maternal branch. The couple was reassured of a very low recurrence risk in the case of future pregnancy and a prenatal test was offered considering the possibility of gonadal mosaicism. In this case, recovery of a biological sample from the dead child and identification of the causative $R B 1$ mutation allowed the correct recurrence risk assessment and prenatal test to be offered.

\section{Discussion}

Our study identified a mutation in the $R B 1$ gene in 13 out of 35 patients $(37 \%)$. The mutation detection rate in either familial or bilateral RB was 59\% (13/22). Comparison of data obtained in the present study with the frequency and type of $R B 1$ mutations reported in the literature is shown in Table 2. While the frequency of mutations detected varies over a wide range, the pattern of mutations is very similar in various populations, the most predominant categories being nonsense and frameshift mutations (Table 2). An interesting aspect of this work is the high rate of novel mutations found (11 out of 13 mutations) (Table 1). A possible explanation is the different geographical provenance of our cohort of patients, since this is the first report of $R B 1$ mutational screening in an Italian population. Further studies on a wider group of Italian patients will be necessary to assess whether this represents a casual or real observation.

Heterozygous carriers of a nonsense or frameshift mutation almost invariably develop multiple RB foci in both eyes (Lohmann 1999). However, in some families a significant proportion of carriers remain unaffected (reduced penetrance), and many affected individuals have only unilateral RB or benign retinocytomas (reduced expressivity) (Harbour 2001).

Immunological or other host-mediated factors were early hypotheses proposed for incomplete penetrance. It is now clear that most mild cases are associated with mutations leading to a reduction in the quantity or quality of cellular pRB activity. Most families showing incomplete penetrance have distinct $R B 1$ mutations such as missense and in-frame mutations that do not result in premature termination codons (Sakai et al. 1991; Onadim et al. 1992; Lohmann et al. 1994; Bremner et al. 1997; Otterson et al. 1997; Ahmad et al. 1999; Lohmann and Gallie 2004). However, the case of incomplete penetrance described in Fig. 1a bears a frameshift mutation. This data lead us to speculate that other factors besides the type of $R B 1$ mutation may determine the penetrance of the disease. In a recent study, it has been demonstrated that diversity in the level of expression of the disease-associated allele could be a potential moderator of phenotypic variation among individuals (Murakami et al. 2004).

Another feature of the disease is that tumours sometimes apparently regress spontaneously, leaving characteristic scars on the retina. An alternative explanation is that scars represent retinomas - a more benign form of the disease (Onadim et al. 1992). Retinoma is clinically defined as a grey translucent mass extending into the vitreous from the retina, associated with calcified foci and pigment-epithelium hyperplasia. In some cases, calcified vitreous seeding has been reported. Retinoma and RB have the same genetic implications; in fact the same mutations can cause both conditions depending on the maturation status of the retinoblasts. When $R B 1$ loss occurs in relatively mature retinoblasts it results in benign hyperplastic nodules or retinomas; when the same events arise in immature retinoblasts, the result is malignant RBs (Gallie et al. 1982). Previous studies indicate a retinoma frequency of $8.5 \%$ among RB patients and their families. We have identified a case of retinoma in a cohort of 19 individuals bearing an $R B I$ mutation $(5.2 \%)$. The difference may be due to the restricted number of cases analysed.

Homozygous loss of $R B 1$ gene function is necessary and sufficient for the clinical manifestation of RB. The increased risk of second cancers observed in patients with germline $R B I$ mutations arises because the number of sequential "hits" required for clonal expansion of a malignancy would have been reduced by one (Kaye and Harbour 2004).

Germinal mutations in the $R B 1$ gene are also implicated in increased mortality associated with other tumours. As previously reported, additional tumours develop in $4.4 \%$ of cases during the first 10 years of follow-up, in $18.3 \%$ after 20 years, and in $26.1 \%$ after 30 years (Roarty et al. 1988). Early-onset second cancers, such as midline intracranial primitive neuroectodermal tumours, generally arise months to years after the diagnosis of hereditary RB. Osteosarcomas and softtissue sarcomas usually arise during adolescence, whereas melanomas tend to occur in patients in their 20s or older (Wong et al. 1997). The case reported in Fig. 1d had RB followed by osteosarcoma. It is well known that patients with RB during early childhood are at risk of developing osteosarcoma during adolescence. It is reported that osteosarcoma occurred 1.2 years earlier inside than outside the radiation field in patients who underwent external beam irradiation with a mean of $12.2 \pm 5.7$ and $13.4 \pm 3.3$ years, respectively (Chauveinc et al. 2001). In our case, an ethmoidal osteosarcoma arose in the proband at 24 years although it was within the irradiation field.

The case reported in Fig. 1c was diagnosed with RB followed by the development of ethmoidal adenocarcinoma at the age of 22. Adenocarcinoma of the ethmoid sinus is rare, representing only $4-8 \%$ of malignancy of 
the paranasal sinuses. Only one case was reported in 1980 , a patient with a papillary adenocarcinoma of the ethmoid sinus arising 30 years after a high-dose radiotherapy for bilateral RB (Rowe et al. 1980). In our case, we know that the proband was treated in the past with chemotherapy and radiotherapy. Previous studies reported the presence of similar numbers of second primary tumours both inside and outside the irradiation fields, suggesting that irradiation is not the major risk factor for all additional tumours (Moll et al. 2001). The adenocarcinoma and osteosarcoma in the cases reported in Fig. 1c and d, respectively, both arose within the irradiation field. These data focus attention on the importance of irradiation as a cofactor in addition to the RBI mutation in the development of second primary tumours.

The case described in Fig. 1e shows how essential the availability of any type of patient tissue is when analysis is requested after the patient's death by family members interested in risk assessment. In the reported case, the availability of the cordonal blood of the affected dead child allowed us to ascertain the presence of a constitutive pathogenic $R B 1$ mutation in this patient. Subsequent analysis of the parental DNA led us to assume a "de novo" origin of the mutation. All these data allowed us to accurately estimate the recurrence risk for the couple in case of future pregnancies. The couple was reassured of a very low recurrence risk. Moreover, the identification of the causative mutation allows us to offer a prenatal test to avoid the effect of gonadal mosaicism. Finally, this experience strengthens the importance of collecting biological samples from each subject in order to ascertain the cause of the genetic disease even postmortem and in order to provide the family with accurate recurrence risk.

The mutation rate reported in our study is quite similar to those found by other groups using the same methodological approach (Table 2). The most frequently used screening method in these studies is the SSCP technique, whose sensitivity in general may not be high enough to detect all changes. More efficient techniques such as DHPLC or direct sequencing may provide a better estimate of the frequency of point mutations in the patient population studied. However, two groups that performed the analysis by direct sequencing did not have a higher mutation detection rate (Table 2). A higher detection rate has been reported using a combination of approaches (Richter et al. 2003; Houdayer et al. 2004). Beside the techniques used for detection analysis, other explanations for our high rate of negative cases can be given. In our cohort of negative patients, 13 were unilateral sporadic and so they may bear either two somatic mutations or have an $R B I$ mutation in a mosaic state. The absence of detectable mutation could also be explained by the presence of rearrangements not visible by the real-time assay used in this study. In fact, our probe designed towards exon 17 reveals only whole-gene deletions and partial deletions including exon 17. Other phenomena, such as epigenetic alterations or a possible inactivation of $R B 1$ through mutation of non-coding sequences, may also be invoked to explain the cause of disease in the remainder of the patients, especially in our six bilateral sporadic and three familial cases.

\section{References}

Ahmad NN, Melo MB, Singh AD, Donoso LA, Shields JA (1999) A possibile hot spot in exon 21 of retinoblastoma gene predisposing to a low penetrant retinoblastoma phenotype? Ophthalmic Genet 20:225-231

Alonso J, Garcia-Miguel P, Abelairas J, Mendiola M, Sarret E, Vendrell MT, Navajas A, Pestana A (2001) Spectrum of germline $R B 1$ gene mutations in Spanish retinoblastoma patients: phenotypic and molecular epidemiological implications. Hum Mutat 17:412-222

Alonso J, Frayle H, Menendez I, Lopez A, Garcia-Miguel P, Abelairas J, Sarret E, Vendrell MT, Navajas A, Artigas M, Indiano JM, Carbone A, Torrenteras C, Palacios I, Pestana A (2005) Identification of 26 new constitutional $R B 1$ gene mutations in Spanish, Colombian, and Cuban retinoblastoma patients. Hum Mutat 25:99

Blanquet V, Turleau C, Gross-Morand MS, Senamaud-Beaufort C, Doz F, Besmond C (1995) Spectrum of germline mutations in the $R B 1$ gene: a study of 232 patients with hereditary and non hereditary retinoblastoma. Hum Mol Genet 4:383-388

Bremner R, Du DC, Connolly-Wilson MJ, Bridge P, Ahmad KF, Mostachfi H, Rushlow D, Dunn JM, Gallie BL (1997) Deletion of RB exons 24 and 25 causes low-penetrance retinoblastoma. Am J Hum Genet 61:556-570

Chauveinc L, Mosseri V, Quintana E, Desjardins L, Schlienger P, Doz F, Dutrillaux B (2001) Osteosarcoma following retinoblastoma: age at onset and latency period. Ophthalmic Genet 22:77-88

Choy KW, Pang CP, Yu CB, Wong HL, Ng JS, Fan DS, Lo KW, Chai JT, Wang J, Fu W, Lam DS (2002) Loss of heterozygosity and mutations are the major mechanisms of $R B 1$ gene inactivation in Chinese with sporadic retinoblastoma. Hum Mutat 20:408

Comings DE (1973) A general theory of carcinogenesis. Proc Natl Acad Sci USA 70:3324-3328

Cowell JK, Smith T, Bia B (1994) Frequent constitutional C to T mutations in CGA-arginine codons in the $R B 1$ gene produce premature stop codons in patients with bilateral (hereditary) retinoblastoma. Eur J Hum Genet 2:281-290

Dalamon V, Surace E, Giliberto F, Ferreiro V, Fernandez C, Szijan I (2004) Detection of germline mutations in argentine retinoblastoma patients: low and full penetrance retinoblastoma caused by the same germline truncating mutation. J Biochem Mol Biol 37:246-253

Gallie BL, Ellsworth RM, Abramson DH, Phillips RA (1982) Retinoma: spontaneous regression of retinoblastoma or benign manifestation of the mutation? Br J Cancer 45:513-521

Gallie BL, Campbell C, Devlin H, Duckett A, Squire JA (1999) Developmental basis of retinal-specific induction of cancer by RB mutation.Cancer Res 1[Suppl 7]:1731s-1735s

Hansen MF, Koufos A, GAllie BL, Phillips RA, Fodstad Ø, BrØgger A, Gedde-Dahl T, Cavenee WK (1985) Osteosarcoma and retinoblastoma: a shared chromosomal mechanism revealing recessive predisposition. Proc Natl Acad Sci USA $82: 6216-6220$

Harbour JW (2001) Molecular basis of low-penetrance retinoblastoma. Arch Ophthalmol 119:1699-1704

Hogg A, Onadim Z, Baird PN, Cowell JK (1992) Detection of heterozygous mutations in the $R B 1$ gene in retinoblastoma patients using single-strand conformation polymorphism analysis and polymerase chain reaction sequencing. Oncogene 7:1445-1451 
Houdayer C, Gauthier-Villars M, Lauge A, Pages-Berhouet S, Dehainault C, Caux-Moncoutier V, Karczynski P, Tosi M, Doz F, Desjardins L, Couturier J, Stoppa-Lyonnet D (2004) Comprehensive screening for constitutional $R B 1$ mutations by DHPLC and QMPSF. Hum Mutat 23:193-202

Kaye FJ, Harbour JW (2004) For whom the bell tolls: susceptibility to common adult cancers in retinoblastoma survivors. J Natl Cancer Inst 3:342-343

Kiran VS, Kannabiran C, Chakravarthi K, Vemuganti GK, Honavar SG (2003) Mutational screening of the RBI gene in Indian patients with retinoblastoma reveals eight novel and several recurrent mutations. Hum Mutat 22:339

Knudson AG Jr (1971) Mutation and cancer: statistical study of retinoblastoma. Proc Natl Acad Sci USA 68:820-823

Klutz M, Horsthemke B, Lohmann DR (1999) RB1 gene mutations in peripheral blood DNA of patients with isolated unilateral retinoblastoma. Am J Hum Genet 64:667-668

Lee EY, To H, Shew JY, Bookstein R, Scully P, Lee WH (1988) Inactivation of the retinoblastoma susceptibility gene in human breast cancers. Science 241:218-221

Liu Z, Song Y, Bia B, Cowell JK (1995) Germline mutations in the $R B 1$ gene in patients with hereditary retinoblastoma. Genes Chromosomes Cancer 14:277-284

Lohmann DR (1999) RBI gene mutations in retinoblastoma. Hum Mutat 14:283-288

Lohmann DR, Gallie BL (2004) Retinoblastoma: revisiting the model prototype of inherited cancer. Am J Med Genet C Semin Med Genet 129:23-28

Lohmann DR, Brandt B, Hopping W, Passarge E, Horsthemke B (1994) Distinct RBI gene mutations with low penetrance in hereditary retinoblastoma. Hum Genet 94:491-496

Lohmann DR, Brandt B, Hopping W, Passarge E, Horsthemke B (1996) The spectrum of $R B 1$ germ-line mutations in hereditary retinoblastoma. Am J Hum Genet 58:940-949

Lohmann DR, Gerick M, Brandt B, Oelschlager U, Lorenz B, Passarge E, Horsthemke B (1997) Constitutional RBI-gene mutations in patients with isolated unilateral retinoblastoma. Am J Hum Genet 61:282-294

Moll AC, Imhof SM, Schouten-Van Meeteren AY, Kuik DJ, Hofman P, Boers M (2001) Second primary tumors in hereditary retinoblastoma: a register-based study, 1945-1997: is there an age effect on radiation-related risk? Ophthalmology 108:1109-1114

Murakami Y, Isogai K, Tomita H, Sakurai-Yageta M, Maruyama T, Hidaka A, Nose K, Sugano K, Kaneko A (2004) Detection of allelic imbalance in the gene expression of hMSH2 or RB1 in lymphocytes from pedigrees of hereditary, nonpolyposis, colorectal cancer and retinoblastoma by an RNA difference plot. J Hum Genet 49:635-641

Onadim Z, Hogg A, Baird PN, Cowell JK (1992) Oncogenic point mutations in exon 20 of the $R B 1$ gene in families showing incomplete penetrance and mild expression of the retinoblastoma phenotype. Proc Natl Acad Sci USA 89:6177-6181

Otterson GA, Chen W, Coxon AB, Khleif SN, Kaye FJ (1997) Incomplete penetrance of familial retinoblastoma linked to germ-line mutations that result in partial loss of RB function. Proc Natl Acad Sci USA 94:12036-12040

Richter S, Vandezande K, Chen N, Zhang K, Sutherland J, Anderson J, Han L, Panton R, Branco P, Gallie B (2003) Sensitive and efficient detection of $R B I$ gene mutations enhances care for families with retinoblastoma. Am J Hum Genet $72: 253-269$

Roarty JD, McLean IW, Zimmerman LE (1988) Incidence of second neoplasms in patients with bilateral retinoblastoma. Ophthalmology 95:1583-7

Rowe LD, Lane R, Snow JB Jr (1980) Adenocarcinoma of the ethmoid following radiotherapy for bilateral retinoblastoma. Laryngoscope 90:61-69

Sakai T, Toguchida J, Ohtani N, Yandell DW, Rapaport JM, Dryja TP (1991) Allele-specific hypermethylation of the retinoblastoma tumor-suppressor gene. Am J Hum Genet 48:880888

Sambrook J, Fritsch EF, Maniatis T (1989) Molecular cloning: a laboratory manual, 2nd edn. Cold Spring Harbor Laboratory Press, Cold Spring Harbor, NY

Scheffer H, Van Der Vlies P, Burton M, Verlind E, Moll AC, Imhof SM, Buys CH (2000) Two novel germline mutations of the retinoblastoma gene $(R B 1)$ that show incomplete penetrance, one splice site and one missense. J Med Genet 37:E6

Shimizu T, Toguchida J, Kato MV, Kaneko A, Ishizaki K, Sasaki MS (1994) Detection of mutations of the RB1 gene in retinoblastoma patients by using exon-by-exon PCR-SSCP analysis. Am J Hum Genet 54:793-800

Sugano K, Yoshida T, Izumi H, Umezawa S, Ushiama M, Ichikawa A, Hidaka A, Murakami Y, Kodama T, Suzuki S, Kaneko A (2004) Outpatient clinic for genetic counseling and gene testing of retinoblastoma. Int J Clin Oncol 9:25-30

Tsai T, Fulton L, Smith BJ, Mueller RL, Gonzalez GA, Uusitalo MS, O'Brien JM (2004) Rapid identification of germline mutations in retinoblastoma by protein truncation testing. Arch Ophthalmol 122:239-248

Vogel F (1979) Genetics of retinoblastoma. Hum Genet 52:1-54

Wadayama B, Toguchida J, Shimizu T, Ishizaki K, Sasaki MS, Kotoura Y, Yamamuro T (1994) Mutation spectrum of the retinoblastoma gene in osteosarcomas. Cancer Res 54:30423048

Wong FL, Boice JD Jr, Abramson DH, Tarone RE, Kleinerman RA, Stovall M, Goldman MB, Seddon JM, Tarbell N, Fraumeni JF Jr, Li FP (1997) Cancer incidence after retinoblastoma. Radiation dose and sarcoma risk. JAMA 278:1262-1267 